\title{
Contribution à une histoire du concept d'hellénisme de Chateaubriand à Théodore Reinach
}

Contribution to a history of the concept of Hellenism from Chateaubriand to Théodore Reinach

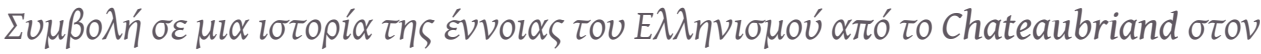
Théodore Reinach

\section{Christophe Corbier}

\section{OpenEdition}

\section{Journals}

Édition électronique

URL : https://journals.openedition.org/ceb/17386

DOI : $10.4000 / c e b .17386$

ISSN : 2261-4184

Éditeur

INALCO

Édition imprimée

ISBN : 9782858313693

ISSN : 0290-7402

Référence électronique

Christophe Corbier, «Contribution à une histoire du concept d'hellénisme de Chateaubriand à

Théodore Reinach », Cahiers balkaniques [En ligne], 47 | 2020, mis en ligne le 21 août 2020, consulté le 06 juillet 2021. URL : http://journals.openedition.org/ceb/17386 ; DOI : https://doi.org/10.4000/ceb. 17386

Cahiers balkaniques est mis à disposition selon les termes de la Licence Creative Commons Attribution - Pas d'Utilisation Commerciale 4.0 International. 


\title{
Contribution à une histoire du concept d'hellénisme de Chateaubriand à Théodore Reinach
}

\author{
Contribution to a history of the concept of Hellenism \\ from Chateaubriand to Théodore Reinach

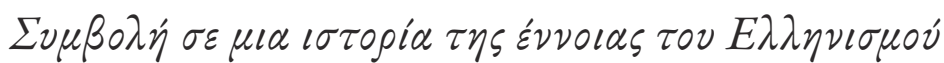 \\ $\alpha \pi \dot{~}$ to Chateaubriand $\sigma \tau o v$ Théodore Reinach
}

Christophe Corbier CNRS - IReMus UMR 8223

Comme l'avait remarqué Henri Peyre dès 1932, « hellénisme », en français, est une notion vague ${ }^{1}$. Quand elle est convoquée dans le champ de l'histoire littéraire, cette notion désigne généralement, et de façon assez imprécise, l'imitation des œuvres grecques par-delà l'antithèse classicisme/romantisme. Cependant, il s'agit seulement d'un usage possible du mot: «hellénisme » a pu aussi revêtir les sens de «culture grecque », ou de «science de l'Antiquité », ou d'époque hellénistique. Mais cette notion problématique a fini par être considérée par Arnaldo Momigliano comme un concept embarrassant, sinon vain ${ }^{2}$.

$\mathrm{Si}$ le rapport entre ces diverses significations n'est pas immédiatement perceptible, nous ne devons pas pour autant renoncer à observer les relations qui se nouent entre elles durant le $\mathrm{XIX}^{\mathrm{e}}$ siècle. Il faut revenir d'abord aux premières mentions du terme dans le champ historiographique. L'une des tâches des historiens et des philosophes de l'époque romantique a été de définir l'hellénisme

1. Peyre, 1932, p. 4.

2. Momigliano, 1983, p. 383-384. 


\section{CAHIERS BALKANIQUES}

pour en faire un concept opératoire sur le plan de la philosophie de l'histoire ${ }^{3}$. On sait ce que le mot «hellénisme » doit à Herder, à Hegel, et surtout à Johann Gustav Droysen, auteur d'une Geschichte des Hellenismus en trois volumes (1833-1842), qui relate l'affrontement entre Macédoniens et cités helléniques, l'histoire des conquêtes d'Alexandre et la constitution de la société et de l'État hellénistiques sous le règne des diadoques jusqu'en 220 avant notre ère. Il s'agit pour Droysen de réévaluer l'histoire de la Grèce postclassique en montrant que «l'hellénisme » est une période de grande vitalité préparant l'avènement du christianisme: sa vision théologico-philosophique d'inspiration hégélienne le conduit à réinterpréter l'histoire hellénistique en rejetant la thèse de la décadence grecque après la bataille de Chéronée et en montrant la fusion de l'Orient et de l'Occident accomplie par Alexandre ${ }^{4}$.

Le terme «hellénisme », au sens qu'il revêt chez Droysen, se développe en français à la fin du $\mathrm{XIX}^{\mathrm{e}}$ siècle, en partie grâce à Droysen lui-même : après la première édition de son ouvrage, l'historien allemand le révise et le fait rééditer en 1877-1878, puis en 1880. Il prend enfin connaissance, avant son décès en 1884, de la traduction française qui en a été entreprise entre 1883 et 1885 sous le titre Histoire de l'Hellénisme et sous la direction d'Auguste Bouché-Leclercq, qui venait de publier en 1880 la traduction de l'Histoire grecque d'Ernst Curtius : Droysen a lui-même apporté d'ultimes corrections en vue de l'édition française du livre 5 .

Est-ce à dire qu'en langue française, « hellénisme » ait attendu cette édition pour prendre le sens de « civilisation grecque débordant sur le monde », selon l'expression de Bouché-Leclercq (qui conserve les guillemets autour du mot en 1883$)^{6}$ ? Au contraire, si le terme a pu être transféré de l'allemand au français dans les années 1880, c'est parce que les hellénistes français avaient déjà entrepris d'en redéfinir le contenu en utilisant un de ces concepts en -isme qui éclosent dans la seconde moitié du XIX $\mathrm{X}^{\mathrm{e}}$ siècle pour essentialiser des pratiques culturelles et définir un courant philosophique, un mouvement artistique ou une doctrine politique. Le mot français « hellénisme » est donc assez chargé de valeurs pour que nous nous interrogions sur la pluralité de ses significations.

Il faut prendre en compte également le rapport entre «hellénisme » et « philhellénisme ». Comme l'a rappelé Sophie Basch dans Le Mirage grec, un « misophilhellénisme » s'est répandu dans l'opinion française à partir des années

3. Momigliano, Janvier 1935, p. 10-35 ; Bravo, 1968, p. 147-161 ; Canfora, 1987 ; Bichler in SAÏD (dir.), 1991, p. 363-383 ; BRUNEAU, 2002, p. 319-328.

4. Sur les interprétations modernes d'Alexandre le Grand, voir BRIANT, 2011.

5. Droysen, 1883, p. I.

6. Droysen, 1883, p. viI. 
1850 et il a accompagné la formation de la Grèce contemporaine tout autant que les relations avec l'Empire ottoman et la Turquie kémaliste ${ }^{7}$. Toutefois, lorsqu'on ôte les deux préfixes qui induisent une évaluation de la culture hellénique, il reste un mot neutre en apparence, mais qui est chargé de connotations multiples et dont le champ sémantique s'élargit peu à peu au cours du XIX ${ }^{\mathrm{e}}$ siècle. L'hellénisme concerne ainsi les Grecs autant que les Français et les Européens dans leur relation avec une « civilisation » hellénique conçue à la lumière du « miracle grec » et dont «l'esprit » survit à travers les diverses époques de l'histoire occidentale. En cela, on peut procéder avec l'hellénisme à une analyse similaire à celle de l'orientalisme, jadis déconstruit par Edward Saïd.

Devant une question si vaste, nous livrerons dans le cadre restreint de cet article quelques observations sur les changements qui affectent le terme « hellénisme » jusqu'au moment où il a fini par devenir un concept historico-philosophique et recouvrir, en français, un ensemble complexe où se mêlent science de l'Antiquité, philhellénisme, histoire religieuse, théorie esthétique et «Grande Idée » nationaliste.

\section{«L'hellénisme » entre la règle et l'usage}

Commençons par quelques observations lexicologiques. Tandis que l'allemand, par exemple, distingue «Griechentum » et « Hellenismus », les emplois du terme « hellénisme » en français brouillent la limite avec la notion de « grécité » dans la seconde moitié du XIX ${ }^{\mathrm{e}}$ siècle. Rien n'est plus significatif à cet égard que la traduction d'un livre fondamental en France dans l'histoire de l' « hellénisme » : La Naissance de la tragédie à partir de l'esprit de la musique de Nietzsche, qui porte comme sous-titre dans la réédition de 1886 Griechentum und Pessimismus. Les premiers traducteurs du livre, Jacques Morland et Jean Marnold, ont proposé en 1901 : Hellénisme et Pessimisme. La « grécité » que le philologue-philosophe avait voulu mettre au jour en 1872 sur des bases esthétiques et anthropologiques nouvelles à partir de la lutte des pulsions dionysiaque et apollinienne, afin de proposer une nouvelle évaluation de la culture hellénique, avait été résumée par les traducteurs sous le terme d' « hellénisme ».

Or, avant les années 1860, rien n'aurait autorisé un tel emploi de ce mot en français. Ignoré d'Antoine Furetière comme des rédacteurs du Dictionnaire de l'Académie française en 1690, « hellénisme » a été longtemps défini dans un sens purement grammatical : il s'agit d'un idiotisme grec, dont on trouve la trace en latin et dans la Vulgate. « Hellénisme » côtoyait le mot « helléniste », renvoyant

7. BASCH, 1995, p. 493-500. 
d'abord aux «Juifs hellénistes » ayant vécu à Alexandrie sous les Lagides et pendant l'Empire romain ${ }^{8}$. Mais à partir des années 1820, le terme s'enrichit peu à peu. En 1802, pour le lexicographe Pierre-Claude-Victor Boiste, il n'a encore que le sens grammatical traditionnel ${ }^{9}$. En 1828, le Dictionnaire universel de la langue française de Boiste (décédé en 1824) est réédité et augmenté par Charles Nodier; à l'article « hellénisme » est ajoutée la définition qui, au moment de la guerre d'indépendance grecque, résonne avec l'actualité diplomatique et politique: « opinion en faveur des Grecs ${ }^{10}$ ». L'évolution du terme est entérinée quelques décennies plus tard avec les dictionnaires d'Émile Littré et de Pierre Larousse. Dans le tome 2 du Dictionnaire de la langue française édité en 1872-1873, Littré, lexicographe et helléniste, donne une triple définition du mot « hellénisme »:

- tour, expression qui tient au génie de la langue grecque ;

- ensemble des idées et des mœurs de la Grèce ;

- nom donné par l'empereur Julien au paganisme renouvelé dans le IV siècle au contact des idées chrétiennes ${ }^{11}$.

« Hellénisme » est précédé du verbe « helléniser », qui signifie selon Littré : «se livrer à l'étude du grec», « suivre les opinions des Grecs» et « rendre conforme au caractère grec $\gg$. Ces définitions suggèrent que l'hellénisme devient dans les années 1870 un concept aux connotations idéologiques de plus en plus sensibles et un quasi synonyme d'hellénisation, hors de toute

8. Dans l'édition revue et augmentée du dictionnaire de Furetière en 1727, figurent les définitions suivantes: «Hellénisme, s. m. C'est une phrase grecque, par laquelle on exprime en Latin, par une imitation tirée des Grecs, des choses qui ne se peuvent défendre par les règles de la construction Latine. Il y a des hellénismes dans la Vulgate. / Hellénistes. Juifs ou Prosélytes Juifs qui parlaient le Grec, qui habitaient hors de la Judée, et qui lisaient la Bible en Grec dans les Synagogues. Philon était un Helléniste. » Le grammairien Nicolas Beauzée donne la définition suivante dans l'Encyclopédie de Diderot et d'Alembert : «c'est un idiotisme grec, c'est-à-dire, une façon de parler exclusivement propre à la langue grecque, et éloignée des lois générales du langage. » (Diderot et d'Alembert, Encyclopédie, 1756, tome 8, p. 104-105). Définitions semblables dans le Dictionnaire de Trévoux (édition de 1771, tome Iv, p. 772) et dans le Manuel lexique, ou Dictionnaire portatif des mots françois dont la signification n'est pas familière à tout le monde (1788, tome 1, p. 535). Le Dictionnaire de l'Académie (6édition, 1835, p. 884), définit encore l'hellénisme comme « tour, expression, manière de parler empruntée du grec, ou qui tient au génie de cette langue ».

9. Boiste, 1803, p. 210.

10. Boiste, 1828 , p. 349.

11. LitTRÉ, 1874, p. 2001. 
référence à un contexte historique déterminé. En 1872, dans le neuvième tome du Grand Dictionnaire universel du xix ${ }^{e}$ siècle, Pierre Larousse consacre lui aussi un long article à «Hellénisme », qui retrace l'histoire de la Grèce et qui se termine par la mention de trois ouvrages majeurs: l'Histoire de l'bellénisme de Droysen, les Origines du christianisme d'Ernest Havet et L'Hellénisme en France d'Émile Egger ${ }^{12}$. Larousse tient compte des nouvelles significations que le terme a récemment acquises en français : notion historiographique désignant l'époque hellénistique chez Droysen, «hellénisme » concerne aussi la relation avec le judéo-christianisme et l'histoire littéraire française. Nous reviendrons plus loin sur le livre d'Havet qui nourrit en grande partie l'article de Larousse, pour nous arrêter au livre d'Émile Egger, capital pour la définition de l'hellénisme français.

Professeur de littérature grecque à la Faculté des lettres de Paris en 1845, patriarche des études grecques jusqu'à sa mort en 1885, Egger avait donné en 1868-1869 des « Leçons sur l'influence des études grecques dans le développement de la langue et de la littérature française ». Publiées dès la fin de l'année 1869 sous le titre L'Hellénisme en France, ces leçons ont contribué à diffuser le sens nouveau qu'Egger attribue au mot. Dans une note, il rappelle en effet qu' « hellénisme » est encore peu usité, alors qu'il est pourtant attesté depuis Guillaume Budé :

Je ne sais pourquoi ce mot, si commode pour exprimer le génie de la belle antiquité, surtout représentée par la Grèce, n'est pas plus en usage dans notre langue. G. Budé essayait déjà de l'accréditer, au moins sous sa forme latine, dans son livre De transitu Hellenismi ad Christianismum, et le dernier biographe de Budé, M. Rebitté, ne craint pas de l'employer fréquemment dans le sens le plus compréhensif. Le Dictionnaire de M. Littré l'admet, à peu près dans le même sens. On me permettra de suivre ces exemples : aucun mot ne marque plus clairement ni plus brièvement l'ensemble des idées et des faits que nous allons étudier dans ces chapitres de notre histoire littéraire ${ }^{13}$.

Selon Egger, l'hellénisme désigne l' «action exercée sur notre génie par les œuvres du génie grec », une action « tantôt directe et tantôt indirecte », souvent par l'intermédiaire des poètes romains ${ }^{14}$. Par ailleurs, pour lui, les Français détiennent une incontestable autorité dans le champ des études grecques : bien

12. Larousse, 1872 , p. 156-157.

13. EgGER, 1869 , p. 4.

14. Ibid. 
que, depuis la fin du XVIII ${ }^{\mathrm{e}}$ siècle, les Allemands aient bâti la philologie sur de nouvelles bases et revendiqué l'exclusivité de l'héritage hellénique, les Français peuvent se réclamer d'une école de savants tout aussi légitime. Si le modèle germanique a pu inspirer la création de l'École pratique des hautes études en 1868 par Victor Duruy, «l'hellénisme » est pour Egger la preuve qu'il a existé une tradition d'érudition spécifiquement française à l'époque moderne (ce que Renan évoquait lui aussi en 1867 à propos de la Renaissance française et de Port-Royal ${ }^{15}$ ).

La première leçon d'Egger, qui y indique l'orientation générale de son cours, se veut aussi une démonstration de la parenté qui aurait uni la « race grecque » et la « race française ». Cette parenté s'explique par la permanence de caractères ethniques sur deux millénaires, depuis la rencontre entre Phocéens et Gaulois au $\mathrm{VII}^{\mathrm{e}}$ siècle avant notre ère, et par une longue tradition pédagogique et artistique ${ }^{16}$. Ainsi, l' « hellénisme » désigne « un des éléments primitifs et durables de notre génie national ${ }^{17} \gg$, une tradition artistique et scientifique nationale qui, loin d'être morte, reste vivace depuis la colonisation de la côte méditerranéenne par les Grecs. Cette tradition rend possibles des phénomènes récurrents de renaissance, l'hellénisme fournissant aux artistes et aux savants français l'énergie nécessaire pour renouveler leurs méthodes et leurs pratiques. Egger observe donc le développement continu de « l'hellénisme » en France du début du Moyen Âge jusqu'à André Chénier, en s'étendant sur l'humanisme du $\mathrm{XVI}^{\mathrm{e}}$ siècle, moment exceptionnel de renaissance de l'esprit grec dans les lettres françaises.

En tissant des liens entre hellénisme et humanisme, Egger apparaît comme l'un des principaux responsables du nouvel usage du terme dans le champ littéraire, de sorte qu'après lui, le terme d'hellénisme sera employé pour caractériser une influence grecque chez les écrivains français jusqu'au $\mathrm{Xx}^{\mathrm{e}}$ siècle. Cette nouvelle signification est exploitée dès 1874 par Ambroise Firmin-Didot, élève d'Adamantios Coray, auteur de nombreuses études sur l'histoire grecque, et illustre imprimeur philhellène. Dans Alde Manuce et l'hellénisme à Venise, Firmin-Didot évoque l'arrivée des savants byzantins à Venise et en Italie du Nord à la fin du $\mathrm{XV}^{\mathrm{e}}$ siècle : agents du transfert culturel, ou du moins d'une nouvelle translatio studii, entre Constantinople et l'Italie de la Renaissance, ils ont essaimé partout en Europe en fuyant «l'islamisme », ce que Firmin-Didot explique dans des pages consacrées à la « renaissance de l'hellénisme ${ }^{18} \gg$. Chez lui, le terme

\footnotetext{
15. RENAN, 1884, p. 460.

16. EGGER, 1869, p. 11-20.

17. Ibid., p. 4.
}

18. Firmin-Didot, 1874, p. 16-29. 
renvoie autant aux communautés grecques émigrant en Europe qu'à « l'esprit » grec qu'elles diffusent dans tout l'Occident.

L'extension sémantique du mot est confirmée en 1878 par Henry Houssaye. Historien, journaliste et romancier, familier de Leconte de Lisle, Houssaye, qui avait fait le voyage en Grèce en 1868, est un philhellène notoire qui défend avec ardeur la cause de la Grèce contemporaine contre les «turcophiles » et les « mishellènes ${ }^{19}$. Le 6 avril 1878, tandis qu'une intense activité diplomatique se déploie en Europe après la signature du traité de San Stefano (3 mars 1878) pour éviter un conflit entre la Russie et l'Angleterre et pour préparer le congrès de Berlin, Houssaye publie dans le Journal des Débats, organe historique du philhellénisme, un article intitulé L'hellénisme. Il constate que le mot a acquis depuis peu une signification plus vaste que celle que les Académiciens se contentaient de noter :

Le Dictionnaire de l'Académie ne donne le mot hellénisme que dans son acception grammaticale, comme gallicisme ou latinisme; mais l'histoire prend l'hellénisme dans un sens plus large. Là, il est synonyme de génie grec, et il représente l'action de la langue, de la civilisation et de l'esprit des Hellènes sur les peuples étrangers. [...] Les Septante, parlant de l'introduction de l'esprit grec en Palestine, disent manière de conclusion : « Les Grecs ont hellénisé le pays ». Libanius fait mention des «Barbares hellénisés ». De nos jours, M. Egger a consacré la véritable acception du mot hellénisme en le donnant pour titre à la réunion de ses doctes et éloquentes leçons sur l'influence des études grecques dans le développement intellectuel de la France. ${ }^{20}$

La parution de deux livres grecs en français permet à Houssaye de confirmer cette nouvelle signification de « hellénisme », incluant la notion d'hellénisation : Histoire de la civilisation hellénique de Constantin Paparrigopoulos, « dont le vrai titre serait L'Hellénisme ${ }^{21} \gg$, et La Gréce telle qu'elle est de Pierre Moraïtinis. Le livre de Moraïtinis a pour objet de présenter un tableau de la Grèce contemporaine sur la base de statistiques et d'analyses sociales, économiques et culturelles ${ }^{22}$. L'ambition apologétique de l'auteur, qui répond aux critiques récurrentes contre l'État et la société grecs depuis La Grèce contemporaine d'Edmond About (1854),

19. BASCH, 1995, p. 208-211.

20. Houssaye, 6 avril 1878, p. 2.

21. Ibid.

22. BASCH, 1995, p. 210-212. 
fait écho au livre de Paparrigopoulos, publié en France au moment des incursions grecques en Thessalie au nom de la défense des communautés grecques, trois ans avant l'intégration de ce territoire à la nation grecque en 1881 .

L'historien grec infléchit le sens du terme en français pour lui donner une tout autre acception que celle qu'il possédait jusqu'alors : « hellénisme » se substitue à « Grèce » et renvoie à une nation dont l'histoire se développe organiquement ${ }^{23}$. Avec l'hellénisme, Paparrigopoulos impose un concept historico-philosophique permettant d'affirmer l'unité de l'histoire grecque. Dans sa préface, il définit l'hellénisme comme unité culturelle et spirituelle de la Grèce depuis les temps homériques. L'hellénisme est une civilisation (au sens où Guizot, si important pour Paparrigopoulos, l'entendait dans son Histoire de la civilisation en $\left.E_{\text {Europe }}{ }^{24}\right)$ qui se déploie dans le temps et dans l'espace en continuité : on sait que Paparrigopoulos répond ainsi à la thèse de la discontinuité de l'histoire grecque, que Jakob Philipp Fallmerayer avait avancée en 1830 à partir de critères raciaux.

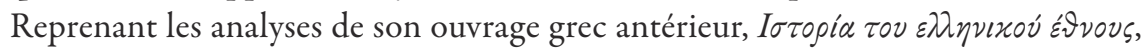
Paparrigopoulos expose l'évolution continue de l'hellénisme depuis l'Antiquité jusqu’à «l'hellénisme moderne » en passant par «l'hellénisme oriental » (correspondant à l'époque hellénistique et romaine) et « l'hellénisme » médiéval (l'Empire byzantin), qu'il veut réhabiliter. Dans la succession de décadences et de renaissances qui scandent l'histoire grecque et qui sont causées par des invasions (Doriens, Slaves, Ottomans), l'hellénisme reste une force constante dont Paparrigopoulos constate la renaissance à partir de 1821. L'ouvrage s'achève par une déclaration enflammée en faveur de la « restauration » de l'hellénisme par une unification territoriale des communautés grecques et par la promotion d'un idéal civilisationnel que la Grèce contemporaine devra proposer, ou imposer, aux nations voisines.

\section{L'hellénisme des hellénistes français}

Si les années 1870 se caractérisent par le reflux du philhellénisme et par un mouvement d'opinion très critique envers la Grèce contemporaine ${ }^{25}$, le philhellénisme connaît parallèlement un renouveau avec la promotion de l'hellénisme, qui franchit clairement une étape à partir de 1878. En cette année décisive pour l'Empire ottoman, en raison de l'émergence d'un Etat bulgare

23. Sigalas in Avlami (dir.), 2001, p. 239-291. Koubourlis, in Beaton \& Ricks (eds), 2009, p. 53-63.

24. KOHLER, 1990, p. 296.

25. BASCH, 1995, p. 173-236. 
et de la redéfinition des frontières dans les Balkans au moment du Congrès de Berlin (13 juin-13 juillet 1878), le mot « hellénisme » prend un sens nouveau en français pour devenir un concept identitaire justifiant les revendications nationales des gouvernements grecs : un «panhellénisme », une «Grande Idée » selon la formule en vigueur depuis que Jean Colettis l'avait employée en janvier 1844, en réponse au panslavisme, ce qui ne manque pas d'ailleurs d'inquiéter certains journalistes français ${ }^{26}$. Cet «hellénisme » signifie l'unité de l'esprit, de la culture, de la « race » grecs et leur permanence à travers les siècles, mais il en vient à désigner aussi les communautés grecques disséminées dans les diverses provinces de l'Empire ottoman et dans les Balkans. Au début des années 1880, le terme français « hellénisme » est donc contaminé par le sens qu'il détient en grec moderne, alors qu'aucun terme spécifique ne se référait auparavant à la défense des intérêts grecs dans les Balkans ni à l'existence d'une population grecque au-delà des frontières actuelles de l'État-nation.

Dans ce changement sémantique, le livre de Paparrigopoulos constitue un jalon important en 1878. Avant la traduction française de L'Histoire de l'hellénisme de Droysen, la signification nouvelle du terme est relayée par les hellénistes français qui ont lu Histoire de la civilisation hellénique. Dans la Revue des Deux Mondes, Émile Burnouf, ancien directeur de l'École française d'Athènes (entre 1867 et 1875), rédige un compte rendu élogieux du livre, où il reprend la définition de l'hellénisme en tant qu'unité de l'histoire grecque ${ }^{27}$. Dans le cadre de l'Exposition universelle qui se tient à Paris à l'automne 1878, le marquis de Queux de Saint-Hilaire, philhellène indéfectible, brosse un tableau très favorable de la Grèce contemporaine, qu'il réalise avec l'aide des statistiques de l'État grec et qu'il fait précéder d'une présentation de l'histoire et de la géographie grecques. Sa principale référence est l'Histoire de la civilisation hellénique, que l'auteur prend pour « guide » afin d'éclairer les étapes de l'histoire grecque ${ }^{28}$. En octobre 1878, dans le Journal des Débats, Émile Egger intervient en faveur des « réclamations historiques de la Grèce » : hellénisme « scientifique » et hellénisme politique se mêlent dans une analyse qui se réfère au livre de Paparrigopoulos. Sans paraître ouvertement favorable au «panhellénisme », Egger commence par brouiller la

26. Voir la réaction d'Ernest Dottain dans le Journal des Débats politiques et littéraires du 20 juin 1878 , p. 2.

27. Lamarre \& Marquis de Queux de Saint-Hilaire, 1878, p. 18-19.

28. Ibid., p. 19. 
frontière entre les deux noms « hellénisme » et « Grèce ${ }^{29} »$, puis il réhabilite l'Empire byzantin, une époque qui a laissé «plus d'un souvenir honorable », avant de mettre l'histoire au service de la politique :

Tant de questions sont en débat aujourd'hui sur les rives du Danube et sur les côtes du Bosphore, tant de passions et d'ambitions rivales s'y entrechoquent, et l'hellénisme a tant de peine à dégager son indépendance et à concentrer ses forces sur le terrain où il florissait jadis, qu'on voudrait au moins éclaircir les questions qui relèvent uniquement de l'histoire ${ }^{30}$.

Egger et Queux de Saint-Hilaire ne sont pas des cas isolés de savants qui mettent leur autorité scientifique au service d'une cause politique à la fin des années 1870 ; un grand nombre d'hellénistes français a été favorable au développement de « l'hellénisme » compris dans cette signification nouvelle. L'une des étapes importantes dans l'essor de cette idéologie scientifique et politique a été la création de l'Association pour l'encouragement des études grecques. Fondée en 1867, cette association s'est donnée pour objectif d'étudier et de mettre en avant toutes les époques de l'histoire grecque et toutes les facettes de la culture hellénique, considérée comme une totalité. Certains des membres fondateurs de l'Association portaient un grand intérêt à l'histoire grecque moderne et contemporaine et entretenaient le souvenir du philhellénisme des années 1820 : outre le marquis de Queux de Saint-Hilaire, Émile Egger et Ambroise Firmin-Didot, on peut mentionner Wladimir Brunet de Presles, auteur de L'Univers. La Grèce depuis la conquête romaine (1860), et Abel Villemain qui, dans un volume des Études d'histoire moderne (1846), avait retracé l'histoire de la Grèce depuis la chute de Constantinople jusqu'à la guerre d'indépendance des années 1820. Toutefois, ni l'un ni l'autre n'avaient fait appel à l'hellénisme comme concept pour interpréter l'histoire de la Grèce moderne et contemporaine.

La situation change à la fin des années 1870 . Le terme « hellénisme », au sens du néo-grec, apparaît en 1877 dans Grèce et Turquie d'Alfred Gilliéron, relation d'une mission archéologique en Albanie, en Macédoine et en Grèce : «L'bellénisme ou l'union en un seul corps des quatre ou cinq millions d'Hellènes

29. « La Grèce, en effet, ou plutôt l'hellénisme, pour nous servir d'un mot commode qui est rentré dans l'usage depuis quelques années, l'hellénisme représente l'humanité entière comme en un fidèle raccourci, avec toutes les qualités et tous les défauts qui sont le fond de notre nature ». (Émile Egger, «Les réclamations historiques de la Grèce », Journal des Débats politiques et littéraires, 14 novembre 1878, p. 3).

30. Ibid. 
ou d'Albanais hellénisés qui peuplent l'Europe et l'Asie antérieure, telle est la généreuse aspiration qui fait battre tous les cœurs de l'Orient grec ${ }^{31} \gg$. Le terme est repris par Léon Hugonnet qui, dans La Grèce et l'hellénisme (1884), en rappelle les deux principales acceptions, l'une politique, l'autre philosophique et religieuse : « Pour les uns, il exprime les intérêts et les aspirations d'une race. Pour d'autres, il résume un ensemble d'idées, de doctrines et de faits caractérisant une des phases principales du génie humain comme l'Égyptianisme, le Romanisme, le Christianisme, l' Islamisme. ${ }^{32}$ »

Quant à l'écrivain grec francophone Dimitri Bikelas, il participe lui aussi à la redéfinition du terme en français. Quand Bikelas narre l'histoire du philhellénisme dans les années 1820, il constate que ce mouvement de soutien aux Grecs a bel et bien disparu après $1830^{33}$. Mais si le philhellénisme est mort, l'hellénisme, lui, reste bien vivant et Bikelas entend le montrer en 1885 aux historiens français réunis au Cercle Saint-Simon pour écouter une conférence sur « Le rôle et les aspirations de la Grèce dans la question d'Orient ». Il s'agit pour Bikelas de définir l'hellénisme dans le cadre d'une réflexion politique et historique. Selon lui, l'hellénisme renvoie à l'Antiquité, dont l'Empire byzantin a été le continuateur avant de sombrer dans les deux derniers siècles de son existence. L'hellénisme, d'après Bikelas (qui s'écarte quelque peu des positions de Paparrigopoulos), repose sur la conjonction d'une langue et d'une nation : l'Empire byzantin a été cimenté par la langue grecque, mais il n'a pas respecté l'essence de l'hellénisme en ce qu'il a été un mélange d'ethnies réunies seulement par une langue d'échange ${ }^{34}$. L'hellénisme véritable est à chercher du côté de la Grèce antique, de sorte que « la révolution grecque est un réveil de l'hellénisme; ce n'est pas la résurrection de l'idée byzantine ${ }^{35} \gg$. De cette thèse doit découler la doctrine de l'État grec en matière de politique extérieure après 1878 : au lieu de la résurrection d'un « empire grec », Bikelas préconise la formation d'un État-nation dont la capitale est, non pas Constantinople, mais Athènes, le vrai centre de l'hellénisme ${ }^{36}$. Cet État s'étendra au sud d'une ligne courant de l'Épire à la Chalcidique ${ }^{37}$, ce qui permettra aux communautés hellénophones de rejoindre leur patrie, d'échapper

31. Gilliéron, 1877, p. 294. HeuZey, 1877, p. 164-166.

32. HugONNET, 1884, p. 319.

33. Bikelas, 1891, p. 346-365. Mitsou, 2015.

34. Bikelas, 1885, p. 11-12.

35. Ibid., p. 20.

36. Ibid., p. 24-25.

37. Ibid., p. 41. 
à la domination bulgare et de former un État à l'image de «l'hellénisme » antique $^{38}$.

Quelques années plus tard, l'helléniste et homme politique Victor Bérard contribue à diffuser le sens nouveau du mot « hellénisme » par son ouvrage plusieurs fois réédité et couronné par l'Académie française, La Turquie et l'hellénisme contemporain (1893). Il évoque les communautés grecques en Albanie, en Macédoine et en Épire, ainsi que les communautés bulgares, albanaises, juives, roumaines disséminées dans les Balkans. Le livre de Bérard, helléniste favorable aux Grecs et aux Arméniens ${ }^{39}$, se veut un compte rendu exact et impartial des modes d'existence et des relations de ces communautés dans des territoires que se disputent alors l'Empire ottoman, la Grèce et la Bulgarie. Mais cette revendication d'impartialité est moins sensible chez ses confrères de l'Association pour l'encouragement des études grecques qui entreprennent de définir les caractéristiques de « l'hellénisme » entre essentialisation de la culture grecque et affirmation d'une filiation de la Grèce et de la France.

Publiés dans la Revue des Études grecques à partir de 1888, les allocutions annuelles des présidents de l'Association leur offrent une bonne occasion de définir un concept d'hellénisme promu au sein de ce groupe formé d'artistes, d'historiens, d'hommes politiques, de professeurs et de commerçants. Dans les années 1890-1900, de nombreux présidents, depuis Jules Girard (1888) jusqu’à Charles Diehl (vice-président en 1911), en passant par Henri Houssaye (1891), Maxime Collignon (1893), Dimitri Bikelas (1895), Michel Bréal (1896), Salomon Reinach (1903), Théodore Reinach (1907), Théophile Homolle (1908), reviennent sur «l'hellénisme », sur ses bienfaits pour la culture française et sur la nécessité d'en répandre largement la connaissance, le plus souvent au nom du «miracle grec ». Ernest Renan a rappelé en avril 1892 l'ambition de cet hellénisme : allier à une « pensée scientifique et critique » l'étude de la Grèce, qui a « tracé le cadre complet, susceptible d'être indéfiniment élargi, de la civilisation humaine », et faire participer à cette entreprise «la Grèce régénérée », en reprenant la tradition philologique des $\mathrm{XV}^{\mathrm{e}}$ et $\mathrm{XVI}^{\mathrm{e}}$ siècles, au moment de «la renaissance de l'hellénisme en Occident $^{40}$ ». En 1894, l'archéologue Maxime Collignon a expliqué de même quel sens possédait l'hellénisme à leurs yeux :

Notre curiosité s'adresse à toutes les manifestations de l'hellénisme, depuis les vestiges d'une histoire primitive, encore

38. Ibid., p. 42.

39. ВASCH (dir.), 2015.

40. Renan, 1892, p. 27-28. 
perdue dans la brume du passé le plus lointain, jusqu'aux temps troublés de la conquête ottomane, depuis les monuments qui nous montrent le premier éveil de la vie grecque et nous reportent aux âges héroïques de la puissance achéenne, jusqu'à ces chroniques en grec barbare où revit pour nous le passé de la Grèce du Moyen Âge, avec ses monastères, ses ascètes et le luxe éclatant de la Byzance impériale. En étendant ainsi son champ d'études, notre Association a le sentiment qu'elle se maintient plus étroitement en communication avec l'Orient hellénique, où règne une activité si féconde ${ }^{41}$.

Les articles publiés dans la Revue des Études grecques avant 1914 témoignent effectivement d'une vision commune et de l'élargissement du concept d'hellénisme, puisqu'on y trouve des études sur toutes les époques de la Grèce, depuis l'Antiquité jusqu'à la Grèce contemporaine, en passant par Byzance et la Grèce moderne. Dès 1888, par ailleurs, la rubrique « Correspondance grecque », dans cette même Revue, est destinée à faire connaître l'actualité politique, culturelle, économique et sociale de la Grèce et elle est tenue par Théodore Reinach puis par Dimitri Bikelas dans les années 1890.

Cette attention constante portée à la Grèce contemporaine conduit les hellénistes français à s'engager de plus en plus nettement en faveur de l'hellénisme, entendu comme idéologie politique. La collusion entre philologie et politique est portée à son comble au début du $\mathrm{Xx}^{\mathrm{e}}$ siècle, quand une grande partie de ces chercheurs (dont Théodore Reinach, Alfred Croiset, Collignon, Diehl, Pottier, Pernot, Houssaye) ainsi que plusieurs hommes politiques (dont Aristide Briand et Georges Clemenceau) se retrouvent au sein de la «Ligue française pour la défense des droits de l'hellénisme », fondée le 22 janvier 1905 autour de Théophile Homolle : le but est de défendre l'hellénisme contre l'Empire ottoman et contre les « autres États chrétiens » (c'est-à-dire la Roumanie et la Bulgarie), au nom de la solidarité franco-grecque ${ }^{42}$. L'hellénisme devient un mot d'ordre politique qui recouvre les intérêts grecs et français en Méditerranée, une «mer gréco-latine » où rayonne la Grèce, nation la plus « civilisée » d'Orient, selon les membres de la Ligue ${ }^{43}$.

41. Collignon, 1894, p. $\mathrm{x}$.

42. L'Hellénisme, $2^{\mathrm{e}}$ année, $\mathrm{n}^{\circ} 2$, $1^{\text {er }}$ février 1905, p. 1-2. BASCH, 1995, p. 344-346.

43. Ibid., p. 3. 
L'autre signification du terme, tout aussi nationaliste et inséparable de la dimension politique, apparaît enfin en 1916 sous la plume d'Alfred Croiset, qui fait paraître alors une brochure sobrement intitulée L'Hellénisme. Pendant la Première Guerre mondiale, tandis que la Grèce est encore neutre, un tel titre pourrait annoncer un texte à contenu politique, au sens où René Puaux, en 1916, s'alarme du « déclin de l'hellénisme » et continue de le définir dans son sens grec moderne ( « la réalisation intégrale de l'unité nationale fondée sur la communauté de langue, de religion, d'origine ethnique et de tradition historique $\left.{ }^{44} \gg\right)$. Mais il n'en est rien. C'est dans un tout autre cadre que Croiset publie cet opuscule d'une quinzaine de pages : l'exposition universelle de San Francisco en 1915.

Peu avant la création de l'Association Guillaume Budé en 1917, ce texte retrace la généalogie d'une science française de l'Antiquité depuis la Renaissance, sous les auspices de l'auteur du De Transitu Hellenismi ad Christianismum. Pour Croiset, qui fut l'un des passeurs de la philologie germanique dans l'université française à la fin du $\mathrm{XIX}^{\mathrm{e}}$ siècle, l'hellénisme désigne précisément la tradition philologique française transmise de Guillaume Budé jusqu'aux savants contemporains. Épousant les vues d'Émile Egger, Croiset affirme que la philologie française a d'abord connu au $\mathrm{XVI}^{\mathrm{e}}$ siècle une floraison exceptionnelle qui s'est prolongée au siècle suivant dans les œuvres de Casaubon, de Scaliger, de Saumaise et des érudits de Port-Royal. Si au XVIII ${ }^{\mathrm{e}}$ siècle, la science de l'Antiquité française reflue, le renouveau des études grecques est décelable à partir des années 1780, et l'effort des savants ne cesse plus pour développer et enrichir une discipline illustrée par Barthélemy, Chateaubriand, Boissonnade, Victor Cousin, Littré, Henri Patin, Renan et tous les hellénistes français de la fin du siècle. Substituant « hellénisme » à « philologie » et à « science de l'Antiquité », Croiset réussit le tour de force de passer sous silence les philologues allemands, dont l'influence paraît nulle sur la science française, mais qu'il avait lui-même admirés dans les années 1880, avant de conclure :

Une revue aussi sommaire ne peut donner qu'une idée très incomplète de l'activité déployée par la France dans le domaine de l'hellénisme. Elle ne sera pourtant pas inutile si le lecteur en tire cette conclusion que le goût de l'antiquité grecque, si enthousiaste au $\mathrm{XVI}^{\mathrm{e}}$ siècle, dans une élite restreinte de savants, est aujourd'hui plus répandu qu'il ne l'a jamais été, et que l'étude des choses helléniques est cultivée par nos savants contemporains dans un

44. Alaux \& Puaux, 1916, p. 13-15. 
esprit plus large, avec des méthodes plus précises et plus sûres qu'elle ne l'était par leurs prédécesseurs ${ }^{45}$.

En 1915, la généalogie de l'hellénisme permet aussi d'affirmer implicitement une solidarité historique entre la France et la Grèce et de justifier l'alliance entre les deux pays contre «l'Allemagne, ennemie de l'hellénisme », comme l'écrira Georges Argyroglo dans un livre de propagande préfacé par Alfred Croiset et Maurice Barrès en 1916.

Jusqu’à la Première Guerre mondiale, les hellénistes français ont déployé tout un éventail de significations autour d'un mot qui devient une arme de propagande politique. Faisant écho au grand récit national proposé par Paparrigopoulos dans son Histoire de la civilisation hellénique, ils ont voulu définir la civilisation hellénique comme une totalité culturelle et spirituelle depuis les temps les plus anciens jusqu'à la période la plus récente, une civilisation dont l'influence bénéfique s'est exercée durablement sur les lettres et la nation françaises.

Mais l'unification de l'histoire, de la science, de la politique et de l'art dans un terme si connoté ne doit pas faire oublier que l'hellénisme n'a pas été conçu uniformément comme une valeur positive au $\mathrm{XIX}^{\mathrm{e}}$ siècle, pas plus dans le champ de la politique que dans celui de l'histoire religieuse. En ce domaine, l'hellénisme a été d'abord une notion polémique, héritée des Pères de l'Église et de l'empereur Julien, comme l'avait bien rappelé le libre-penseur matérialiste que fut Émile Littré dans la troisième définition du terme.

\section{Hellénisme, philhellénisme et paganisme chez Chateaubriand}

Dans le cadre d'une philosophie de l'histoire fondée sur la relation dialectique de deux aires culturelles groupées sous les bannières « Orient » et « Occident », « hellénisme » est devenu un concept opératoire à partir des années 1820-1830. Il a permis de réinterpréter plusieurs événements fondamentaux : migrations et colonisation grecque, contacts entre les Grecs et les autres ethnies du bassin méditerranéen et de «l'Orient», origines du christianisme à l'époque hellénistique. La rencontre entre Grecs et juifs est particulièrement importante pour le concept d' « hellénisme » puisque l'une des toutes premières attestations du mot «hellènismos » se trouve au livre II des Macchabées pour désigner les juifs qui ont abandonné leurs traditions et adopté le mode de vie grec (II, 9, 13 et $\left.19^{46}\right)$. « Hellènismos » pose d'emblée le problème de l'identité et des rapports

45. Croiset, 1916, p. 161.

46. SAÏD, 1991, p. 4-6. Momigliano, 1991, p. 87-136. 
interculturels, ce dont témoigne également le cas des juifs hellénistes mentionnés dans les Actes des Apôtres (vi, 1) et connus à Alexandrie sous les Lagides.

Tout le problème consiste, au cours du $\mathrm{XIX}^{\mathrm{e}}$ siècle, à produire de nouvelles interprétations de l'hellénisme pendant l'époque que nous nommons à présent hellénistique. Il s'agit notamment de réviser une tradition exégétique qui se place du point de vue d'une histoire providentielle et d'une condamnation du paganisme, comme celle que Bossuet avait exposée dans son Discours sur l'histoire universelle (1681). De la découverte de l'hellénisme procède une nouvelle évaluation du terme en français, qu'on peut observer de Chateaubriand à Renan.

Il convient de porter d'abord le regard sur Chateaubriand qui, avant Droysen, a analysé longuement l'hellénisme pour comprendre le passage du paganisme au christianisme. Si Alfred Croiset, en 1915, a pu mentionner Chateaubriand parmi les représentants de l'hellénisme, l'auteur de l'Itinéraire de Paris à Jérusalem entretient toutefois une relation ambivalente avec la Grèce. En 1825, quand il publie la « Note sur la Grèce », il apporte tout le poids de sa notoriété au philhellénisme. Son appel fervent à l'opinion publique et aux gouvernements européens doit les contraindre à soutenir la révolution grecque parce qu'il faut défendre une nation chrétienne contre le Croissant ${ }^{47}$. Le souvenir de l'Antiquité est certes présent dans la lutte des Grecs pour la liberté et le droit contre la tyrannie des Ottomans, lointains héritiers des Perses de Darios et de Xerxès, mais c'est surtout dans l'esprit d'une nouvelle croisade que Chateaubriand appelle à combattre les Turcs. Néanmoins, la solidarité avec les insurgés n'engendre pas de réévaluation complète de la Grèce antique, toujours séparée de la Grèce chrétienne.

Depuis le Génie du christianisme (1802) jusqu'aux Études historiques (1831), le paganisme et la culture gréco-latine font l'objet d'une critique profonde, d'abord au moyen du comparatisme, puis par le biais d'une philosophie de l'histoire exposée dans les Études historiques. Cet ouvrage, qui prolonge les réflexions du romancier des Martyrs, présente une interprétation de l'histoire des premiers siècles du christianisme sur la base de principes philosophiques qui permettent de renouveler la compréhension de l'histoire universelle. Car c'est avec Bossuet, Herder, Hegel, Vico, Ballanche, dont les thèses historico-philosophiques sont résumées dans la préface des Études historiques, que dialogue Chateaubriand ${ }^{48}$. Il propose à son tour un système expliquant les origines de la société moderne, point de mire des Études historiques et du projet inachevé des Discours historiques qui devaient leur succéder.

47. BASCH, 1995, p. 25-31.

48. Chateaubriand, 1861, p. 33-43. 
Toute l'histoire, selon Chateaubriand, est fondée sur «trois vérités 》 qui sont au «fondement de l'ordre social»: la vérité «religieuse », la vérité «philosophique ou l'indépendance de l'esprit de l'homme », la vérité « politique ou la liberté $»^{49}$. Tout le problème des sociétés humaines consiste à unir ces trois vérités, qui constituent la cause de tous les «faits historiques ». Quand elles entrent en conflit, la dysharmonie engendre la révolution et la subversion; quand elles s'accordent, l'ordre social est préservé. La recherche de cette harmonie repose sur une condition : concevoir le christianisme comme « un cercle qui s'étend à mesure que les lumières et la liberté se développent ${ }^{50} \gg$. Autrement dit, le conflit des libertés et la division sociale disparaissent si on ne fait pas, « comme Bossuet », du christianisme « un cercle inflexible ${ }^{51} »$. D'où une périodisation du christianisme en cinq «ères » successives qui montrent son caractère évolutif: «ère morale ou évangélique », «ère des martyrs», « ère métaphysique ou théologique », 《ère politique », «ère » ou 《âge philosophique » qui correspond à la situation actuelle $e^{52}$.

Passant des principes philosophiques à l'analyse historique, Chateaubriand distingue trois «peuples» à l'origine de la société moderne: «païen, chrétien et barbare ». L'objet des Études historiques est de mettre au jour l'évolution qui mène de «l'empire purement latin-romain » fondé par Auguste aux «monarchies barbares», en passant par la transition de «l'empire romain-barbare » au $\mathrm{V}^{\mathrm{e}}$ siècle $^{53}$. Dès la préface, la «marche »de l'histoire est affirmée puisque le christianisme, en détruisant les «deux abominations » de la société païenne, le polythéisme et l'esclavage, en permettant l'émancipation des femmes et en instituant le principe de l'égalité humaine, a favorisé la troisième vérité, la vérité politique, la liberté ${ }^{54}$. Chateaubriand interprète enfin l'invasion des barbares et les premiers temps de la monarchie franque comme le moment historique de la victoire du christianisme sur le paganisme.

C'est dans le cadre de ce système historico-philosophique qu'apparaît le terme « hellénisme » dans la deuxième des Études historiques. Mais quel sens lui confère Chateaubriand ? L'écrivain a lu les Idées sur la philosophie de l'histoire de l'bumanité de Herder dans la traduction qu'Edgar Quinet en avait proposée

49. Ibid., p. 70-71, 101-114.

50. Ibid., p. 70.

51. Ibid.

52. Ibid.

53. Ibid., p. 71.

54. Ibid. 
en 1828. Les historiens de « l'hellénisme » (Momigliano, Bichler, Canfora) ont rappelé le rôle essentiel qu'a joué Herder dans la constitution de « l'hellénisme » au sens historico-philosophique. Le terme, repris de la traduction des Septante, apparaît sous la plume de Herder pour évoquer les juifs hellénistes dont l'influence sur le christianisme a été décisive. Pour Herder, «l'hellénisme » scelle l'union de « l'esprit grec » et du « génie juif » et il permet au christianisme de prendre son essor ${ }^{55}$. En 1828, Edgar Quinet traduit « Hellenismus » par « hellénisme », contribuant à orienter le mot français vers le sens de «culture grecque, mœurs grecques » et de fusion entre Orient et Occident durant l'époque hellénistique. Mais cet emploi est encore rare et, dans Du Génie des religions (1842), Quinet lui-même ne se sert pas du terme « hellénisme » pour définir la religion grecque au moment où elle se mêle aux religions orientales.

Quant à Chateaubriand, qui s'inscrit en 1831 dans la tradition des Pères de l'Église, il garde au mot une connotation péjorative: « hellénisme » désigne une culture gréco-latine fondée sur la philosophie néoplatonicienne et le polythéisme, dont l'empereur Julien s'était fait l'apôtre afin de supprimer le christianisme au milieu du $\mathrm{IV}^{\mathrm{e}}$ siècle. À cette époque, deux forces spirituelles, deux systèmes de pensée, deux puissances politiques se font face, qui peuvent prétendre à représenter les trois vérités de l'histoire. Confondant hellénisme et paganisme, Chateaubriand oppose les « prêtres de l'hellénisme » et les « prêtres de la croix ${ }^{56} \gg$, tout en montrant combien cet « hellénisme » est imprégné des principes et des pratiques du christianisme. Tandis que « le christianisme avait forcé l'hellénisme à l'imitation pour maintenir sa puissance ${ }^{57} »$, « Julien fut le Luther païen de son siècle; il entreprit la réformation de l'idolâtrie sur le modèle de la discipline des chrétiens. Plein d'admiration pour la fraternité évangélique, il désirait que les païens se liassent ainsi d'un bout de la terre à l'autre. ${ }^{58} \gg$ À longueur de pages, Chateaubriand narre les efforts désespérés de Julien pour faire renaître le paganisme, efforts condamnés d'avance, car contraires au sens de l'histoire, c'està-dire à l'établissement définitif du christianisme par sa victoire sur l'hellénisme : «Ainsi s'évanouirent tous les projets de Julien : il entreprit d'abattre la croix, et il fut le dernier empereur païen. L'hellénisme retomba de tout le poids des âges dans la poudre d'où l'avait soulevé à peine une main mal guidée. ${ }^{59} \gg$ Sur le plan

55. Herder, 1828, p. 241-245.

56. Chateaubriand, 1861, p. 251.

57. Ibid., p. 242.

58. Ibid.

59. Ibid., p. 267. 
historique, enfin, la défaite de Julien entraîne la division définitive de l'Orient et de l'Occident et une évolution décisive causée par l'arrivée massive des Barbares dans la partie occidentale ${ }^{60}$.

Pourquoi insister sur le conflit entre «hellénisme » et « christianisme»? Depuis l'Essai sur les révolutions (1797), l'histoire de l'Antiquité constitue une source de réflexions morales et politiques. Ainsi, pour l'historien catholique, la lutte menée par Julien évoque les impasses du protestantisme : l'Apostat et Luther ont imposé un culte intellectuel et philosophique depuis le sommet de l'État, engendrant le «fanatisme » et l'intolérance, alors que le catholicisme universel et populaire était «parti d'en bas ${ }^{61}$. Ensuite, Chateaubriand aperçoit une relation entre la fin de l'Empire romain et l'époque contemporaine, marquée par la contestation voltairienne et philosophique de la vérité religieuse et par le conflit entre la vérité politique et la vérité religieuse depuis la Révolution. «L'hellénisme » de Julien, qui est un « paganisme philosophique ${ }^{62}$ », est lié à des questions politiques et religieuses actuelles : « Il a fallu vous rappeler en détail cette dernière épreuve de l'Église, parce qu'elle fait époque et qu'elle se distingue des autres : elle tient d'une civilisation plus avancée : elle a un air de famille avec l'impiété littéraire et moqueuse qu'un esprit rare répandit au XVIII ${ }^{\mathrm{e}}$ siècle $^{63} \gg$. Enfin, la politique de l'empereur Julien renvoie l'historien à la situation de la France de son temps :

Le polythéisme se trouva sous Julien dans la position où le christianisme se trouve de nos jours, avec cette différence qu'il n'y aurait rien aujourd'hui à substituer au christianisme, et que sous Julien le christianisme était là, prêt à remplacer l'ancienne religion. Inutiles efforts de Julien pour faire rétrograder son siècle : le temps ne recule point, et le plus fier champion ne pourrait le faire rompre d'une semelle ${ }^{64}$.

Ainsi, quelques années avant la publication du livre de Droysen, les Études historiques de Chateaubriand contiennent déjà en germe certains éléments essentiels du concept en français, un concept dont l'usage est requis pour comprendre et éclairer le présent, mais sans référence directe à la Grèce

60. Ibid., p. 269

61. Ibid., p. 82-83.

62. Ibid., p. 268.

63. Ibid., p. 267.

64. Ibid., p. 70. 
contemporaine. Cependant, Chateaubriand n'a pas assez vécu pour assister à la renaissance de «l'hellénisme » ni pour observer la progressive «inversion des valeurs » culminant dans L'Antéchrist de Nietzsche (1888), contestation radicale de toutes les philosophies de l'histoire qui font du christianisme le point d'aboutissement de la civilisation antique.

\section{Hellénisme contre christianisme : Ernest Havet et Ernest Renan}

L'hellénisme devient en effet une valeur positive dans la seconde moitié du siècle chez des auteurs comme Leconte de Lisle, Jules Michelet, Ernest Renan, Louis Ménard (dont Barrès évoquera «l'hellénisme » intégral au début du Voyage de Sparte, et qui est l'auteur entre autres, de l'essai Du Polythéisme antique en 1862, plaidoyer républicain en faveur du paganisme, et d'une Histoire des Israélites en 1884), Anatole France, Ernest Havet. Tous œuvrent dans le même sens par des moyens divers : procéder à une critique du judéo-christianisme et de la société moderne par la valorisation de « l'hellénisme ».

Il faudrait s'arrêter à chacun de ces écrivains. Nous nous concentrerons ici sur Renan et Havet. Tous deux membres de l'Association pour l'encouragement des études grecques dès 1867 , ils ont contribué à réviser les rapports entre « hellénisme » et «judéo-christianisme » en France, et ils entrecroisent leurs travaux sur l'histoire du christianisme à partir de la Vie de Jésus en 1863. Éditeur des Pensées de Blaise Pascal en 1852, libre-penseur, Havet forme dans les années 1860 le projet d'écrire une histoire des origines du christianisme avant Jésus, tandis que Renan développe l'histoire du christianisme primitif depuis Jésus jusqu'à l'époque de Marc-Aurèle dans les sept volumes de son Histoire, avant de la compléter par l'Histoire du peuple d'Israël (1887-1893). Si les périodes étudiées diffèrent, un même postulat gouverne leurs analyses : le rationalisme et la liberté de pensée constituent des normes pour évaluer les cultures et les systèmes religieux. Or le rationalisme, dans l'Antiquité, s'est manifesté dans une culture en particulier : la culture hellénique. Le concept est pris désormais dans un paradigme « hellénisme/ judaïsme-christianisme $\gg$ où la valeur supérieure est conférée au premier terme.

En 1870-1871, Havet intitule « l'hellénisme » la première partie de son livre Le christianisme et ses origines. Contrairement à Droysen et à Chateaubriand, Havet utilise le mot pour se référer à la Grèce tout entière depuis Homère jusqu'à Épicure, et il englobe dans l'hellénisme l'Empire romain jusqu'aux Sévères. Contre les détracteurs du paganisme, Havet affirme que les prémisses du christianisme se trouvent dans la culture gréco-latine de sorte que le christianisme n'est pas un événement absolument nouveau. Ses valeurs fondamentales (émancipation des femmes, égalité, croyance en l'immortalité de l'âme) sont déjà contenues dans 
« l'hellénisme »: le respect manifesté envers les femmes à l'époque homérique, «l'Église pythagorique», Socrate, la philosophie platonicienne, la morale aristotélicienne, le stoïcisme sont autant d'exemples justifiant la haute valeur morale et religieuse de l'hellénisme, et attestant la transmission de la philosophie grecque au christianisme. En somme, pour Havet, l'adversaire de l'hellénisme, c'est moins le christianisme originel que l'Église chrétienne, qui interdit la libre pensée, maintient la croyance au surnaturel et engendre la violence. D'où l'espérance que formule l'helléniste à la fin de la première partie : l'apparition d' « esprits libres, définitivement affranchis de tous les dieux », seul «progrès » permettant de dépasser l'antithèse du paganisme et du christianisme ${ }^{65}$.

Le concept d'hellénisme apparait également chez Renan dès les années 1860. L'auteur de la «Prière à Athéna » est invariablement associé à la thèse du « miracle grec » dont il est le héraut, et sa vision a suscité autant d'admiration que de rejet depuis cent cinquante ans ${ }^{66}$. Mais on doit rester conscient du scandale que constitue l'idée d'un miracle grec avancée par l'ancien séminariste, professeur d'hébreu au Collège de France, suspendu en 1864 sous le régime autoritaire de Napoléon III pour ses vues hérétiques sur l'humanité de Jésus ${ }^{67}$. L'hellénisme, en tant que culture instituée à partir des normes de rationalisme et de beauté, est une valeur à opposer à la clôture du dogme chrétien. Mettre en avant l'hellénisme, c'est adopter une position exactement contraire à celle de Chateaubriand et de la tradition chrétienne. C'est ce qui apparaît au plus fort de la lutte qui oppose Renan au clergé catholique, dans l'Avant-Propos des Apôtres (1866), rédigé au retour de son voyage en Grèce en 1865, et dans un passage de Saint Paul (1868). Renan livre dans ces pages une vision idyllique de l'hellénisme, terme qu'il place parfois entre guillemets pour signaler un usage encore neuf de la notion :

Les terres vraiment helléniques se prêtaient peu à la doctrine de Jésus. [...] Le patriotisme, l'attachement aux vieux souvenirs du pays détournaient les Grecs des cultes exotiques. «L'hellénisme » devenait une religion organisée, presque raisonnable, admettant une large part de philosophie; les « dieux de la Grèce » semblaient vouloir être des dieux universels pour l'humanité.

Ce qui caractérisait la religion du Grec d'autrefois, ce qui la caractérise encore de nos jours, c'est le manque d'infini, de

65. Havet, 1873, p. 333.

66. Vidal-Naquet, 1989, p. 245-266.

67. Momigliano a rappelé combien Droysen avait été choqué par la Vie de Jésus de David Strauss une trentaine d'années plus tôt. Momigliano, 1935, p. 394. 
vague, d'attendrissement, de mollesse féminine ; la profondeur du sentiment religieux allemand et celtique manque à la race des vrais Hellènes. La piété du Grec orthodoxe consiste en pratiques et en signes extérieurs. [...]

La vie, c'est donner sa fleur, puis son fruit; quoi de plus? Si, comme on peut le soutenir, la préoccupation de la mort est le trait le plus important du christianisme et du sentiment religieux moderne, la race grecque est la moins religieuse des races. C'est une race superficielle, prenant la vie comme une chose sans surnaturel ni arrière-plan. Une telle simplicité de conception tient en grande partie au climat, à la pureté de l'air, à l'étonnante joie qu'on y respire, mais bien plus encore aux instincts de la race hellénique, adorablement idéaliste ${ }^{68}$.

La différence entre religion chrétienne et religion grecque ${ }^{69}$ est nuancée par le christianisme oriental, qui aurait hérité en partie de «l'hellénisme », terme qui désigne pour Renan à la fois un esprit et une « race » helléniques ${ }^{70}$, mais aussi une forme de pratique religieuse qui s'est développée aux $\mathrm{II}^{\mathrm{e}}$ et $\mathrm{III}^{\mathrm{e}}$ siècles et dont l'un des représentants serait Plutarque ${ }^{71}$. Renan perçoit en tout cas dans le christianisme oriental des traits constants : il y a une forme de continuité entre les pratiques sociales et religieuses antiques et le culte orthodoxe et la culture populaire de la Grèce contemporaine. «Le Grec », selon Renan, apprécie la vie d'une façon différente de celle du chrétien occidental : « l'hellénisme » désigne une religion sans intérêt pour le surnaturel, phénomène dont on trouve des traces jusque dans les chansons populaires que Fauriel avait recueillies en 1824-182572. Rien de plus éloigné de l'hellénisme que le christianisme institué par le « laid petit Juif », autrement dit Paul de Tarse, dont le séjour à Athènes marque la première rencontre entre christianisme et « hellénisme ».

Ce tableau de «l'hellénisme » contraste quelque peu avec les réflexions que Renan développe vingt-cinq ans plus tard dans l'Histoire du peuple d'Israël. Examinant de nouveau le rapport entre hellénisme, judaïsme et christianisme,

68. RENAN, 1995, p. 616-617.

69. Fraisse, 1979, p. 49.

70. Sur le problème de la race grecque chez Renan et son rapport avec Gobineau, voir Vidal-NaQuet, 1989, p. 258-259; Simon-Nahum, 2008.

71. RENAN, 1995, p. 476-477.

72. Ibid., p. 618. 
il revient cette fois sur la confrontation entre Grecs et juifs sous les Séleucides. Dans cette confrontation qui soulève le problème de la violence et des relations interculturelles aboutissant à la guerre, la perspective diffère sensiblement et la valorisation de l'hellénisme devient un peu plus problématique. Lorsque Renan utilise le terme « hellénisme » au quatrième livre de l'Histoire du peuple d'Israël, il fait référence, de manière classique pour ainsi dire, à la culture hellénique diffusée en Orient, à la politique menée par les successeurs d'Alexandre et à la fusion de l'Orient et de la Grèce. Renan célèbre d'abord le mariage entre Occident et Orient à Alexandrie, entre une « Grèce en décadence » et un « hébraïsme en décadence » qui s'unissent dans une « mysticité » préfigurant le christianisme ${ }^{73}$. Ensuite, dans la toute dernière partie de son livre, «Les Juifs sous la domination grecque », il relit l'épisode des Macchabées à la lumière de ses convictions libérales, rappelées avec force dans les années 1880, peu après sa conversion à l'idéal républicain: comme il le proclame dans la préface des Nouvelles Études d'histoire religieuse (1884), l'État et l'Église doivent être séparés, l'individu respecté dans ses droits, la liberté de conscience défendue et développée par l'instruction, l'exercice de la violence d'État contre les communautés religieuses sévèrement proscrit.

Or, là où Droysen analysait, entre autres, la structuration de l'État hellénistique, Renan insiste sur la séparation irréductible entre les deux cultures dans les années 170-160 et sur la violence d'État qui entraîne la persécution des juifs. Il aborde ainsi un domaine délaissé par l' Histoire de l'hellénisme de Droysen qui, malgré des incursions dans l'histoire romaine et des allusions au judaïsme et aux Arabes, s'interrompait avant l'hellénisation forcée des juifs entreprise par Antiochos Iv Épiphane, la révolte des Macchabées et la réouverture du Temple au culte judaïque (événement célébré lors de la fête de Hanoucca). Au lieu de la fusion Orient-Occident, ce qui s'est produit en effet à ce moment est un affrontement violent entre deux cultures. Comme l'écrit Renan, deux forces sont en présence : «l'hellénisme », dont la « victoire » est complète en Orient vers 175 apr. J.-C., et le « judaïsme », qui, seul, « résiste obstinément ${ }^{74} »$. On pourrait croire d'abord que Renan penche pour les Grecs : le parti juif est « hostile au rationalisme $\operatorname{grec}^{75} \gg$, il rejette la littérature, la science, l'art helléniques, tout autant que le mode de vie grec (bains, jeux, soins du corps). Les communautés situées dans le territoire des Séleucides sont décrites comme «de petits États tyranniques », et rappellent les « communautés de raïas de l'Empire ottoman, où

73. RENAN, 1893, p. 206-207.

74. Ibid., p. 241.

75. Ibid. 
l'individu est sous le pouvoir absolu de son clergé ${ }^{76} \gg$. La Torah est un « mauvais $\operatorname{code}^{77} \gg$, un idéal dont l'application est concrètement impossible, tandis que le droit grec, comme le droit romain, est rationnel. Autrement dit, « il y a contradiction entre une société se prétendant fondée sur une révélation divine et la large société humaine ne connaissant que les liens du droit et de la raison ${ }^{78} \gg$.

Cette contradiction apparemment sans issue sur le plan historique se manifeste à travers la persécution des juifs sous Antiochos IV Épiphane, dont Renan brosse un portrait peu flatteur : pour l'historien libéral, Antiochos Épiphane « commit la faute la plus grave que puisse commettre un souverain, qui est de s'occuper de la religion de ses sujets ${ }^{79} \gg$. Mais, par-delà les événements dramatiques (interdiction des rites judaïques, hellénisation de la société) culminant avec «l'abomination de la désolation » (culte de Zeus dans le Temple), ce moment décisif de l'histoire antique voit la naissance d'une nouvelle croyance préfigurant le christianisme. Le problème capital de cette époque est d'ordre théologique et métaphysique : qu'en est-il de la récompense des justes et du châtiment des méchants ? Israël n'est pas coupable de la persécution d'Antiochos, ce qui provoque une crise dans l'interprétation des origines de la faute et du mal. De là naît l'idée d'une vie éternelle et d'un jugement des méchants après la mort. D'où l'existence de deux croyances chez les juifs : les uns adoptent la croyance en l'immortalité, les autres la rejettent, selon qu'ils acceptent l'héritage du passé ou qu'ils embrassent une logique rationnelle et calculatrice : « Israël continuera son miracle, qui est de produire des sages parfaits sans l'immortalité. Il y aura toujours des Juifs qui se trouveront récompensés, quand ils auront la richesse, l'aisance, les joies de la vie ; mais la logique voulait une satisfaction ${ }^{80}$. »

La domination de l'hellénisme, jusque dans ses erreurs violentes, a été féconde non pas tant parce qu'il y a eu un syncrétisme religieux anticipant sur l'union de la philosophie platonicienne et du protochristianisme, mais parce qu'elle a causé par réaction une nouvelle définition de la foi en l'avenir qui détient une valeur universelle :

L'israélitisme, reposant sur cette doctrine immorale quel' homme à qui il arrive un malheur est coupable, est obligé de reculer et de dire le mot qu'il résistait tant à prononcer depuis des siècles : « La

76. Ibid., p. 243.

77. Ibid.

78. Ibid., p. 244.

79. Ibid.

80. Ibid., p. 254-255. 
vie éternelle ». Le messianisme, l'apocalyptisme vont maintenant marcher à pas de géants. Ce qui est fondé, en particulier, c'est le christianisme. Les deux idées fondamentales de Jésus, le royaume de Dieu et la résurrection, sont complètement formulées. L'esprit de martyre est créé. [...] Vivent les excès ! Vivent les martyrs ! ce sont eux qui tirent l'humanité de ses impasses, qui affirment quand elle ne sait comment sortir du doute, qui enseignent le vrai mot de la vie, la poursuite des fins abstraites, la vraie raison de l'immortalité ${ }^{81}$.

Renan, dans cet éloge inattendu du martyre où fleurissent les mots en $-i s m e^{82}$, fait de la contradiction entre les deux cultures l'origine du christianisme: l'enseignement de Jésus n'a pas surgi ex nibilo par l'action révolutionnaire d'un homme divin, mais il a été annoncé par la mutation du judaïsme entré en contact et en lutte avec l'hellénisme. Élément central d'une évolution historique menant du paganisme au christianisme, l'hellénisme contraint les juifs à une réaction puissante: ce n'est pas la philosophie grecque qui alimente le dogme, mais la pression des circonstances historiques et la nécessité d'une réponse pratique à l'interrogation sur le mal. Sur le plan métaphysique et moral, on pourrait même entrevoir une supériorité du judaïsme sur le platonisme qui nourrira plus tard les premiers Pères de l'Église, parce que le «miracle » d'Israël résout le problème embarrassant de la résurrection des corps par une « forme de foi à l'immortalité » qui rejoint celle du dernier Renan ${ }^{83}$.

C'est ainsi que l'auteur des Souvenirs d'enfance et de jeunesse a mis à distance les connotations nationalistes et politiques de «l'hellénisme » pour s'en tenir à sa dimension historique et religieuse, tout en affirmant encore une fois la grandeur de l'hellénisme dans son discours prononcé devant les membres de l'Association pour l'encouragement des études grecques en avril 1892.

\section{En guise de conclusion: Théodore Reinach et le devenir de l'hellénisme}

Le concept d' « hellénisme » trouve au début du $\mathrm{Xx}^{\mathrm{e}}$ siècle l'un de ses plus grands défenseurs en la personne de Théodore Reinach. Dans le parcours qui mène de la simple acception grammaticale à un concept possédant une épaisseur politique, historique, esthétique et scientifique, les écrits de Reinach constituent un autre jalon important. Helléniste de confession juive, Reinach a tenté en effet de trouver

81. Ibid., p. 256.

82. RÉTAT, 2005, p. 112-121.

83. RENAN, op. cit., p. 255-256. 
des applications pratiques au concept d'hellénisme dans la sphère du judaïsme par son action au sein de l'Union libérale israélite, dans la vie politique et culturelle française contemporaine par son mandat de député de la Savoie, et dans la vie scientifique par ses multiples travaux embrassant la quasi-totalité de l'hellénisme, au sens que lui avait conféré Alfred Croiset.

L'un de ses textes-manifestes en ce domaine est le discours qu'il prononce en tant que président de l'Association pour l'encouragement des études grecques en 1907. Reinach y recense tous les signes d'intérêt portés à la Grèce à son époque, mais il voit surtout dans l'art, dans la politique, dans la science, l'influence de la Grèce. Renchérissant sur les déclarations de Renan à propos du miracle grec et de la nécessité d'opérer des « renaissances » dans la continuité de la Grèce, Reinach appelle ses contemporains à une «inoculation d'hellénisme ${ }^{84} \gg$. Vice-président de la Ligue française pour la défense des droits de l'hellénisme en 1905, aux côtés de Théophile Homolle et de Georges Clemenceau, Théodore Reinach est sensible à la vitalité de la Grèce moderne : il salue les travaux des archéologues grecs dans une conférence prononcée à la Ligue, « La Grèce fouillée par les Grecs » (1907).

Histoire et politique s'unissent également dans un volume dirigé par Adolphe Reinach, le neveu de Théodore, en 1914, et intitulé L'bellénisation du monde antique. Parmi les contributeurs, outre Théodore et Adolphe Reinach, on trouve Alfred Croiset et Paul Jouguet, qui publient une étude préfigurant le livre que le papyrologue consacrera à l'hellénisation de l'Égypte en 1928. Si Adolphe Reinach évoque la colonisation grecque en Provence, Théodore Reinach, éditeur des œuvres complètes de Flavius Josèphe avant 1914, s'intéresse quant à lui à « l'hellénisme en Syrie » et aux persécutions d'Antiochos Épiphane. Malgré quelques différences par rapport à l'interprétation de Renan, il avance une idée similaire : le christianisme surgira de ce moment de crise du judaïsme et réalisera la fusion de l'hellénisme et de l'hébraïsme.

De l'histoire hellénistique à la vie contemporaine, le lien n'est pas rompu : Théodore Reinach estime qu'une « inoculation d'hellénisme » doit aussi être effectuée dans le judaïsme, d'une manière certes plus pacifique que celle qui avait été violemment imposée dans l'Antiquité sous les Séleucides. Dans « Religion et Beauté », conférence prononcée à l'Union libérale israélite en 1922, l'helléniste indique une voie pour rénover les rites du judaïsme, selon une conception moderniste de la religion qu'il avait énoncée dès les années 1900 : associer à la piété traditionnelle la quête de la beauté en se référant à la théorie platonicienne

84. Reinach, 1908, p. XV. 
des Idées, telle qu'elle est exposée dans Le Banquet par Diotime ${ }^{85}$. Quant à l'art, Théodore Reinach, concepteur de la villa Kérylos entre 1902 et 1908, a voulu aussi proposer une renaissance de la tragédie athénienne avec sa traduction des Perses d'Eschyle, mise en musique par Maurice Emmanuel sous le titre de Salamine, et qui a été créée à l'Opéra de Paris en 1929.

Pour Reinach, l'hellénisme est un concept qui s'applique tantôt à une période historique, tantôt à une idéologie politique contemporaine, tantôt à une essence grecque qui, par son caractère transhistorique, exerce toujours sa force au $\mathrm{Xx}^{\mathrm{e}}$ siècle. Ses textes sont l'une des expressions les plus logiques d'un système qui a acquis sa cohérence dans les années 1870-1880. Ils sont le produit d'une idéologie qui n'est pas seulement une forme d'hellénomanie artistique ou de retour à l'Antiquité néo-classique. Les prises de position de Reinach montrent en tout cas que l'idéal de neutralité axiologique du savant a été constamment battu en brèche par «l'hellénisme » jusqu'aux années 1920.

Il reste à réfléchir au devenir du mot «hellénisme » au $\mathrm{xx}^{\mathrm{e}}$ siècle. Depuis les années 1960, l'hellénisme a fait l'objet d'une critique radicale de la part des ethnologues et des anthropologues, dressés contre les vues hellénocentrées des philologues: les attaques de Marcel Detienne contre les «miradors» et les « barbelés » dressés entre 1850 et 1870 autour de la Grèce antique sont portées au nom du comparatisme et du rapprochement entre anthropologie et histoire ${ }^{86}$. Au demeurant, le comparatisme n'avait pas empêché un représentant majeur de «l'école de Cambridge », l'helléniste Gilbert Murray, de varier de nouveau le thème de l'hellénisme après la Seconde Guerre mondiale dans Hellenism and the Modern World (1952), inspiré par Arnold Toynbee.

Par ailleurs, àl'inverse del'histoire de la littérature conçueà la manière d'Egger et de ses successeurs, les théoriciens ont voulu privilégier l'activité du lecteur, le jeu des citations et des reprises, l'intertextualité, tandis que les stratégies d'appropriation de la Grèce antique ont remplacé la notion d'influence, qui implique un rapport hiérarchique entre une origine prestigieuse et des imitateurs marqués par un modèle de perfection. En outre, une philosophie de la déconstruction comme celle de Jacques Derrida a remis en cause le concept traditionnel d'humanisme en interrogeant à nouveaux frais le rapport entre « hellénisme » et « hébraïsme » et le lien qui «nous» unit à ces « autres» que sont les Grecs de l'Antiquité. À cela s'ajoute enfin le fait que le reflux progressif des études grecques en France a accompagné l'affaiblissement inexorable de l'hellénisme politique depuis la

85. Reinach, 1922; Birnbaum, 1994, p. 25-27; Poujol, 2007, p.65-81; Simon-Nahum, 2008, p. 36-38.

86. Detienne, 2001, p. 137-138. 


\section{CAHIERS BALKANIQUES}

252 La presse allophone dans les Balkans

Catastrophe de 1922 jusqu'à la crise de Chypre en 1974 ; la substitution d'une image touristique de la Grèce à l'image « classique » véhiculée par l'hellénisme a été également un phénomène important dont il faut tenir compte ${ }^{87}$. Toutes ces réactions, très diverses, contre l'hellénisme attestent en tout cas la force qu'avait acquise ce terme, devenu un concept à partir des années 1870 , grâce à l'action particulièrement efficace des hellénistes français.

\section{Bibliographie}

\section{Monographies}

Alaux Louis-Paul, Puaux René, 1916, Le Déclin de l’hellénisme, Payot, Paris.

Basch Sophie, 1995, Le Mirage grec, Hatier, Paris.

BAsch Sophie (dir.), 2015, Portraits de Victor Bérard, École française d'Athènes, Athènes, $320 \mathrm{p}$.

Bikelas Demetrios, 1885, Le rôle et les aspirations de la Gréce dans la question d'Orient, Au Cercle Saint-Simon, Paris.

Birnbaum Pierre, 1994, Les fous de la République, Points-Seuil, Paris, 512 p.

Boiste Pierre-Claude-Victor, 1803, Dictionnaire universel de la langue française avec le latin et Manuel d'orthographe et de néologie, $2^{\mathrm{e}}$ édition, Chez Desray, Paris.

Boiste Pierre-Claude-Victor, 1828, Dictionnaire universel de la langue française, $7^{\mathrm{e}}$ édition, Paris.

Briant Pierre, 2011, Alexandre des Lumières, Gallimard, Paris, 752 p.

Chateaubriand François-René de, 1861, Études historiques, in CEuvres complètes, tome 9, Paris, Garnier frères. 
CHÈze Mathilde, 2013, La France en Grèce: étude de la politique culturelle française en territoire hellène du début des années 1930 à 1981, Inalco, Paris, URL : https://tel.archives-ouvertes.fr/tel-00966630.

Croiset Alfred, 1916, L’Hellénisme, dans La Science Française, Tome II, Larousse, Paris.

DalÈgre Joëlle, 2006, La Grèce depuis 1940, L'Harmattan, Paris, 254 p.

Droysen Johann Gustav, 1883, Histoire de l'Hellénisme, I, Ernest Leroux, Paris.

Egger Émile, 1869, L'Hellénisme en France, Didier, Paris.

Firmin-Didot Ambroise, 1874, Alde Manuce et l'hellénisme à Venise, Didot, Paris.

Fraisse Simone, 1979, Renan au pied de l'Acropole, Nizet, Paris.

Gilliéron Alfred, 1877, Grèce et Turquie. Notes de voyage, Sandoz et Fischbascher, Paris.

Havet Ernest, 1873, Le christianisme et ses origines (2 édition), Lévy, Paris.

Herder Johann Gottfried, 1828, Idées sur la philosophie de l'histoire de l'humanité, tome 3, traduction d'Edgar Quinet, Levrault, Paris.

Hugonnet Léon, 1884, La Grèce nouvelle. L'hellénisme, son évolution, son avenir, Degorce-Cadot, Paris.

Lamarre Clovis \& Marquis de Queux de Saint-Hilaire, 1878, La Grèce et l'Exposition de 1878, Delagrave, Paris.

Larousse Pierre, 1872, Grand Dictionnaire universel du xix siècle, tome IX, Administration du Grand Dictionnaire universel, Paris.

Lit ré Émile, 1873-1874, Dictionnaire de la langue française, tome 2, Hachette, Paris. 


\section{CAHIERS BALKANIQUES}

Momigliano Arnaldo, 1991, Sagesses barbares, Gallimard, Folio-Histoire, Paris, $208 \mathrm{p}$.

Peyre Henri, 1932, Bibliographie critique de l'Hellénisme en France de 1843 à 1870, Yale University Press, New Haven, Connecticut.

Renan Ernest, 1995, Histoire des Origines du Christianisme, I, Laffont, Paris.

Renan Ernest, 1893, Histoire du peuple d'Israël, IV, Paris, Calmann-Lévy.

RÉTAт Laudyce, 2005, L'Israël de Renan, Peter Lang, Bruxelles, 208 p.

SAÏD Suzanne, 1991, Ellinismos, E. J. Brill, Leyden, 402 p.

\section{Articles et contributions à des ouvrages collectifs}

Bichler Reinhold, 1991, „Über die Geschichte des Hellenismus-Begriffs in der deutschen Historiographie. Leitende Gedanken, Probleme, Perspektiven“, in

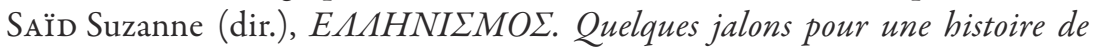
l'identité grecque, Brill, Leiden, p. 363-383.

Bikelas Dimitri, 1891, «Le Philhellénisme en France », Revue d'histoire diplomatique, p. 346-365.

Bravo Benedetto, 1968, Philologie, histoire et philosophie de l'histoire. Étude sur J. G. Droysen, historien de l'Antiquité, Académie polonaise des sciences, Varsovie, $410 \mathrm{p}$.

Bruneau Michel, 2002, « Hellénisme, Hellinismos : nation sans territoire ou idéologie ? », Géocarrefour, Vol. 77 n 4, p. 319-328.

Canfora Luciano, 1987, Ellenismo, Laterza, Biblioteca di cultura moderna, Michigan University, $121 \mathrm{p}$.

Collignon Maxime, 1894, « Allocution », Revue des Études grecques, tome VII.

Detienne Marcel, 2001, « Rentrer au village. Un tropisme de l'hellénisme ? », L'Homme, janvier-mars 2001, n' 157 , p. 137-150. 
EGGER Émile, 1878, « Les réclamations historiques de la Grèce », Journal des Débats politiques et littéraires, 14 novembre 1878, p. 3.

Heuzer Léon,1877, «Voyage de M. Gilliéron en Épire », Comptes rendus des séances de l'Académie des Inscriptions et Belles-Lettres, $21^{\mathrm{e}}$ année, $\mathrm{n}^{\circ} 2$, p. 164-166.

Houssaye Henri, 1878, «L'hellénisme », Journal des Débats politiques et littéraires, 6 avril 1878, p. 2.

Kohler Denis, 1990, « Naissance de l'historiographie grecque moderne », in Espagne Michel \& Werner Michael (éd.), Philologiques i, Contribution à l'histoire des disciplines littéraires en France et en Allemagne au xix siècle, Maison des Sciences de l'Homme, Paris, 427 p.

Koubourlis Iannis, 2009, "European historiographical influences upon the young Konstantinos Paparrigopoulos”, in Beaton Roderick, Ricks David (eds), The making of modern Greece: nationalism, romanticism, and the uses of the past (1797-1896), Farnham, Ashgate, p. 53-63, 284 p.

Mitsou Marie-Élisabeth, 2015, « Négoce et transfert culturel. Dimitrios Bikélas et le réseau intellectuel franco-grec dans la seconde moitié du $\mathrm{XIX}^{\mathrm{e}}$ siècle », Rives méditerranéennes [en ligne, 50].

Momigliano Arnaldo, 1983, « Droysen entre les Juifs et les Grecs », Problèmes d'historiographie antique et moderne, Gallimard, Paris, p. 383-401.

Momigliano Arnaldo, 1935, «Genesi storica e Funzioni attuale del concetto di Ellenismo », Giornale critico delle filosofia italiana, Janvier 1935, p. 10-35.

Poujol Catherine, 2007, « Les débuts de l'Union libérale israélite (1895-1939). Le pari de moderniser le judaïsme français », Archives Juives, 2007/2, Vol. 40, p. 65-81.

ReINACH Théodore, 1908, «Allocution », Revue des Études grecques, XXI, p. XIV-XVII.

ReINACH Théodore, 1922, Beauté et religion. Allocution prononcée au Temple de l'Union libérale le 21 mai 1922, s. 1. n. d. 


\section{CAHIERS BALKANIQUES}

La presse allophone dans les Balkans

Renan Ernest, 1884, «Port-Royal », Nouvelles études d'histoire religieuse, Calmann-Lévy, p. 453-498.

RenAN Ernest, 1892, « Discours », Revue des Études grecques v, p. 27-28.

Sigalas Nikos, 2001, «Hellénistes, hellénisme et idéologie nationale. De la formation du concept d'"hellénisme" en grec moderne », in Avlami Chryssanta (dir.), L'Antiquité, un exemplum contesté ? L'Harmattan, Paris, p. 239-291, 356 p.

Simon-Nahum Perrine, 2008, «L'Orient d'Ernest Renan: de l'étude des langues à l'histoire des religions », Revue germanique internationale [En ligne], 7 .

Vidal-Naquet Pierre, 1989, «Renan et le miracle grec », in La Démocratie grecque vue d'ailleurs, Champs-Flammarion, Paris, p. 245-266, 432 p.

Résumé : comme l'avait remarqué Henri Peyre dès 1932, « hellénisme », en français, est une notion vague; aussi nous livrerons-nous dans le cadre restreint de cet article à quelques observations sur les changements qui affectent le terme « hellénisme » jusqu'au moment où il a fini par recouvrir un ensemble complexe où se mêlent science de l'Antiquité, philhellénisme, histoire des origines du christianisme, esthétique et « Grande Idée » nationaliste.

Mots-clefs: hellénisme, philhellénisme, Johann Gustave Droysen, Chateaubriand, Ernest Renan, Théodore Reinach

Abstract: As Henri Peyre had remarked since 1932, "Hellenism" in French is a vague notion; so we shall give ourselves in the limited scope of this article to a few observations on the changes which affect the term "Hellenism" until the moment when it has finally covered a complex complex which combines science of antiquity, philhellenism, history origins of Christianity, aesthetics and nationalist "Great Idea".

Keywords: hellenism, philhellenism, Johann Gustave Droysen, Chateaubriand, Ernest Renan, Theodore Reinach

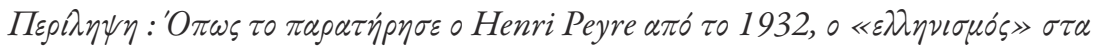

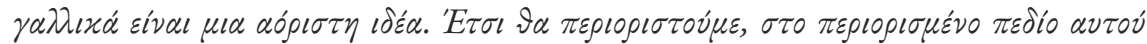

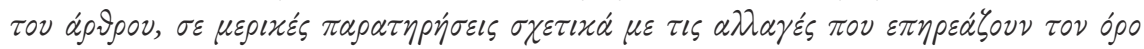

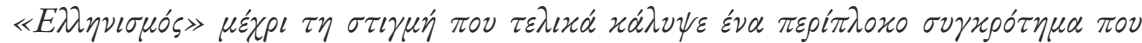




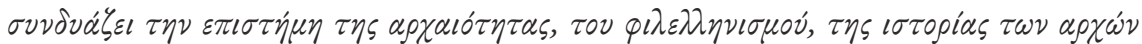

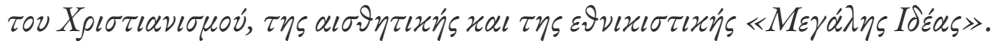

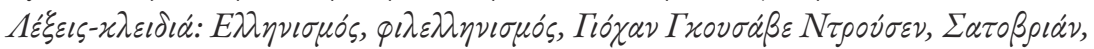

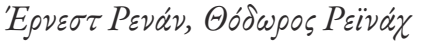

Anahtar Kelimeler: Helenizm, Fihellenizm, Johann Gustave Droysen, Chateaubriand, Ernest Renan, Theodore Reinach

Клучни зборови: Хеленизам, Филеленизам, Јохан Густаве Аројсен, Шатоубрианд, Ернест Ренан, Теодор Реинах 